Bentham open
CrossMark
Content list available at: www.benthamopen.com/TOBIOTJ/
DOI: $10.2174 / 1874070701610010258$

RESEARCH ARTICLE

\title{
Pollutant and Microorganism Removal From Water by Hydrodynamic Cavitation
}

\author{
Zhimeng Liu, Mengfu Zhu ${ }^{*}$, Cheng Deng, Hongbo Su, Ping Chen and Zheng Wang* \\ Institute of Medical Equipment Academy of Military Medical Sciences NO.106, Wandong Road, Hedong District, \\ Tianjin, China
}

\begin{abstract}
Hydrodynamic cavitation can effectively remove organic pollutants and microorganisms from water. Organic compound degradation and water disinfection removal rate is related to reaction time and operating temperature. Removal rate can be improved by increasing the reaction time or raising the operating temperature. Under our experimental conditions, the removal rate of colority, COD and petroleum pollutants was $80.0 \%, 72.13 \%$ and $70.00 \%$, respectively. In addition, Escherichia coli removal rate was higher than $99.99 \%$. As a new water treatment process, hydrodynamic cavitation can be utilized alone or in combination with other water treatment processes, showing broad application prospects.
\end{abstract}

Keywords: Escherichia Coli, Hydrodynamic cavitation, Oxidation, Petroleum pollutant, Water treatment.

\section{INTRODUCTION}

Hydrodynamic cavitation is a novel water treatment technology based on cavitation and has become a very interesting topic in the recent years [1,2]. Cavitation is defined as the phenomenon of formation, growth and subsequent collapse of microbubbles or cavities when the liquid encounter shrinking device in extremely small intervals of time (milliseconds), then release enormous energies [3,4]. When liquid passes through a constriction, such as orifice plates or venture tubes, the local pressure drops below the saturated vapor pressure of the liquid at the operating temperature [5,6]. This results in vaporization of the part liquid or escapes of the dissolved gas in liquid which can form bubbles stream or cavities [7]. The bubbles or cavities are transferred by the liquid and shrink and eventually collapse instantly when the ambient pressure increases, large amount of energies are released then.

Cavitation is a liquid-gas phase transition occurring locally in a liquid medium and can produce extremely complicated physical and chemical effects $[8,9]$. Once the cavitation bubbles collapse, they produce high temperature and pressure, strong shock waves as well as micro jets, releasing enormous energy instantaneously. Under the extreme conditions of very high pressure and temperature, water molecules present within the cavities dissociate into $\bullet \mathrm{OH}$ radicals and oxidize pollutant molecules [10]. After years of research, cavitation is generally acknowledged as a promising technology applicable in numerous areas such as cleaning, emulsion, water treatment and other fields [11 13].

In the recent years, research results show that hydrodynamic cavitation can effectively reduce COD (Chemical Oxygen Demand), TOC (total organic carbon) and UV254 in water. Furthermore, the microbial removal rate was higher than $90 \%$ [14 - 17]. However, hydrodynamic cavitation application in water treatment is still at laboratory scale. To best of our knowledge, equipments for water treatment utilizing hydrodynamic cavitation have not been developed yet [18]. Therefore, an experimental platform for hydrodynamic cavitation water treatment was designed on the basis of reaction

\footnotetext{
* Address correspondence to this author at the Institute of Medical Equipment Academy of Military Medical Sciences NO.106, Wandong Road, Hedong District, Tianjin China; E-mail: zmf323@163.com
} 
mechanism of forming cavitation. The removal performance of petroleum pollutants, colority, COD, and Escherichia coli was evaluated. The results from this study are expected to contribute to the development of equipment for industrial water treatment utilizing hydrodynamic cavitation.

\section{EXPERIMENT}

\subsection{Materials and Instruments}

Crude petroleum was obtained from the Jilin Oilfield of China. The reagents of carbon tetrachloride, anhydrous sodium sulfate, potassium permanganate, peptone, beef extract, agar, sodium chloride and others were of analytical reagent grade (AR). Sodium oxalate was used as reference. E. coli was provided by the National Bio-Protection Engineering Center.

The instruments of an ultraviolet-visible spectrophotometer (DR5000, HACH Corporation), a colorimeter (SD9012AB, Guangzhou Hangxin instrument co., LTD), an infrared oil content analyzer (JDS-105U, Jilin Beiguang Analytical Instrument Factory), a pH meter, an incubator, an autoclave, a conductivity detector and other detectors were used.

\subsection{Experimental Setup}

The hydrodynamic cavitation experimental setup in this study is shown in Fig. (1a). It is a closed system including a holding tank, a main pass, a bypass, a reciprocating pump of power $1.1 \mathrm{~kW}$ and two control valves. The hydrodynamic cavitation reactor with an orifice plate is the core structure. The water in the tank is returned to the pipeline using a pump and then shunted. A by-pass line is provided to control the liquid flow through the main lines. Part of the water flows along the main line into the cavitation reactor and then back to the tank again. The other part of the water flows back to the tank directly through the bypass. The flow rate and pressure are adjusted by using Valve 2. Pressure gauges are provided to measure the inlet pressure (Pressure Gauge1) and the fully recovered downstream pressure (Pressure Gauge 2). Furthermore, the main experimental parameters are as follows: flow rate of $2.0 \mathrm{~m}^{3} / \mathrm{h}$, inlet water pressure of $0.25 \mathrm{MPa}$ and water tank capacity of $50 \mathrm{~L}$.
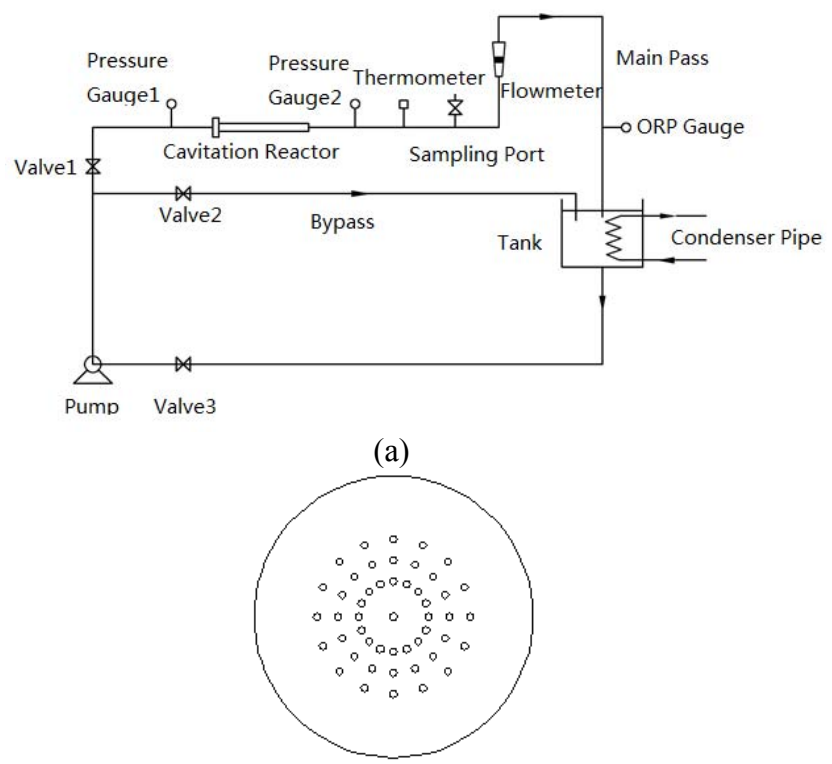

(b)

Fig. (1). Diagram of the hydrodynamic cavitation experimental setup (a) and multi-hole orifice (b).

The distribution of the holes on the multi-hole orifice plate with one hole in the center and the other holes adopted radial distribution regularity method (Fig. 1b). The basic parameters are as follows, the number of holes of 49 , the pore size of $1.00 \mathrm{~mm}$, orifice plate thickness of $4.00 \mathrm{~mm}$, total area of the orifice plate of $38.47 \mathrm{~mm}^{2}$ and the area ratio $\beta$ of orifice plate holes area and pipeline cross-sectional of 0.048 . When water flows through the orifice plate, the pressure 
decreased and flow rate increased, then cavitation was generated.

\subsection{Methods}

Thirty liters of petroleum wastewater of $100 \mathrm{mg} / \mathrm{L}$ was prepared. The colority, COD and petroleum concentration of the petroleum wastewater before and after hydrodynamic cavitation treatment were measured for the removal rate calculations. The colority and the COD were detected according to the provisions of China's national standard GB11903 and GB11914, respectively. Oil content was measured through infrared light metering instrument.

Twenty liters of purified water was inoculated with E. coli to a certain cell density and then treated by the hydrodynamic cavitation reactor. $1 \mathrm{ml}$ of water sample was sampled before and after treatment and cultured on a Petri dish for 24 hours at $37^{\circ} \mathrm{C}$. Viable counts were recorded and E. coli removal rate was calculated.

\section{RESULTS}

\subsection{Colority Removal}

Colority, from soluble or insoluble color contaminants in water, is a key indicator of water quality. Petroleum is a mixture of a variety of organic and inorganic compounds. Therefore, the colority of a petroleum wastewater prepared by crude petroleum was very high. The colority of the oil wastewater was mainly caused by soluble organic matters, suspended colloid, iron ion, manganese ion and particulate matters. When water temperature was $25^{\circ} \mathrm{C}$ and the initial colority was 50.0 PCU. Water colority reduced and colority removal rate increased with time (Fig. 2). The removal rate was more than $80.0 \%$ after 3 hours treatment. When the oil sewage flew through the orifice cavitation reactor, the materials that induced colority in water reacted with the oxidizing agents which were generated during the process of cavitation. Iron, manganese and other inorganic ions formed insoluble remainders by oxidation. The unsaturated functional groups and $\mathrm{c}=\mathrm{c}$ double bonds of colored dissolved organic matters were destroyed through oxidation reaction, which removed the true colority of oil wastewater. This illustrated that hydrodynamic cavitation could reduce the colority of water by changing the structure and character of colored substance. Therefore, water colority could be decreased effectively by the hydrodynamic cavitation.

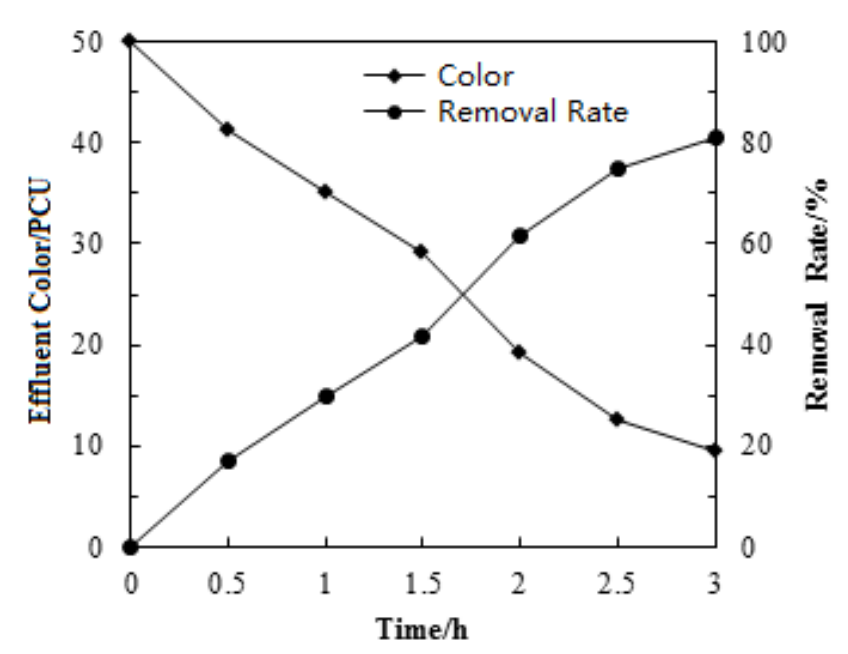

Fig. (2). Colority removal with time.

\subsection{COD Removal}

Chemical oxygen demand (COD) is referred to the consumption of oxidizing agents when water is treated under certain conditions with certain strong oxidants. COD is a indicator to measure organic reducing substances in water. The reducing agents in water include inorganic and organic matters. However, the amount of organic matters was much more than inorganic matters in water. Hence, COD is a measure indicator of the organic matters' content in water. The higher value of COD indicates that the water is more seriously contaminated by organic pollutants. For $30 \mathrm{~L}$ of 
petroleum wastewater with an initial COD of $95.7 \mathrm{mg} / \mathrm{L}$ at $25^{\circ} \mathrm{C}, \mathrm{COD}$ decreased and COD removal rate increased with time (Fig. 3). After 1.5 hours of treatment, the COD removal rate was higher than $40.0 \%$. COD was removed by the - $\mathrm{OH}$ radicals generated during the hydrodynamic cavitation process. As more $\cdot \mathrm{OH}$ radicals were generated with time, COD removal rate increased with time. Nonetheless, $\bullet \mathrm{OH}$ reacted with easily oxidized organic matters, only part of them were oxidized to $\mathrm{CO}_{2}$ and $\mathrm{H}_{2} \mathrm{O}$ directly. The other persistent organic matters which were not easy to be completely oxidized were converted into intermediates or into small molecular organic matters from macromolecular organic compounds. These organisms were still the components of COD, showing that COD can't completely remove by hydrodynamic cavitation.

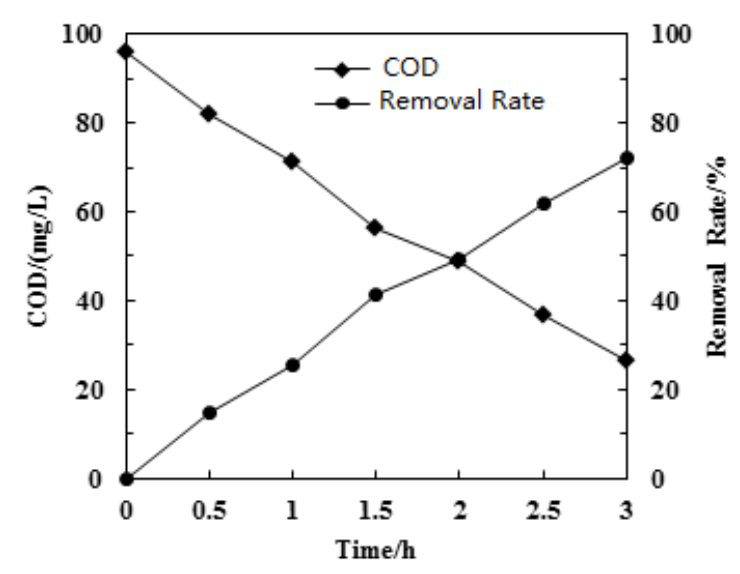

Fig. (3). COD removal with time.

\subsection{Petroleum Removal}

\subsubsection{Effect of Reaction Time on Petroleum Removal}

Petroleum contains hundreds of organic compounds which were generated from debris of plants or animals in the different historical periods of the earth formation. Organics in petroleum are mainly alkanes, cyclanes, aromatic compounds and other hydrocarbons. These petroleum organic macromolecules are converted to small organic molecules or oxidized to carbon dioxide and water. Fig. (4) shows the petroleum removal experiments by cavitation progress at $25{ }^{\circ} \mathrm{C}$ and with an initial petroleum concentration of $98.73 \mathrm{mg} / \mathrm{L}$. Petroleum removal rate increased with time and was higher than $50.0 \%$ after 1.5 hours of reaction. It was precisely the oxidation of the hydrodynamic cavitation that destroyed the major molecular structure of the petroleum organic components, which lead to a good removal effects.

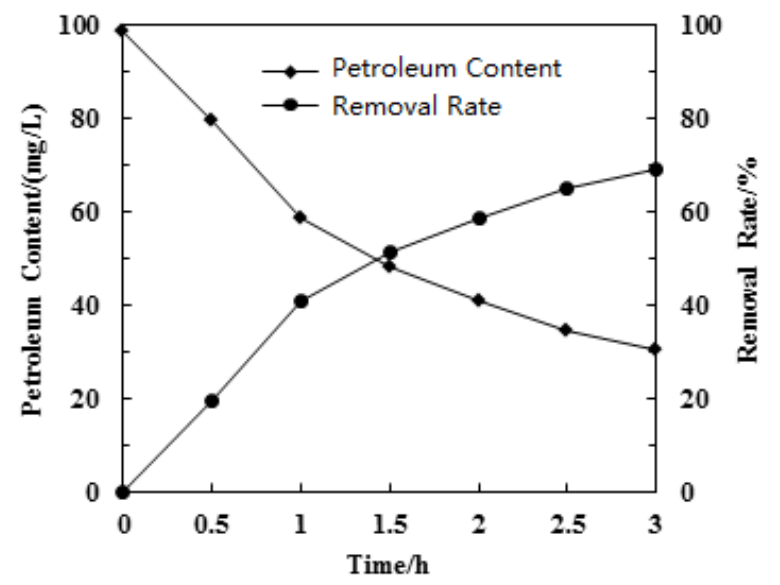

Fig. (4). Effect of reaction time on petroleum removal. 


\subsubsection{Effect of Water Temperature on Petroleum Removal}

Water temperature is one of the main factors which influence hydrodynamic cavitation efficiency. With water temperature increasing, water vapor pressure increased and cavitation effect was enhanced. Therefore, better cavitation effect could be achieved with the higher temperature. In the meantime, the water molecules diffused faster with the increase of water temperature, which also promoted organic pollutant oxidation. Fig. (5) shows the influence of water temperature on the oil pollutant removal rate experiment with an initial petroleum concentration of $98.73 \mathrm{mg} / \mathrm{L}$ and reaction time of $2 \mathrm{~h}$, the petroleum removal rate increased not much from $58.77 \%$ to $64.48 \%$ with the water temperature increased from $25^{\circ} \mathrm{C}$ to $50^{\circ} \mathrm{C}$. Therefore, emphasis should not be placed on raising water temperature to raise removal rate for the sake of energy efficiency. A hydrodynamic cavitation process can also achieve a satisfactory petroleum removal rate at room temperature.

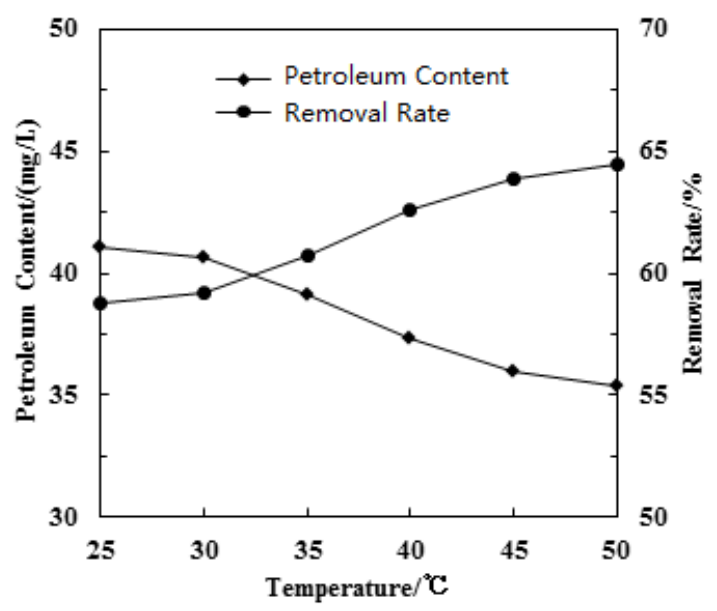

Fig. (5). Effect of water temperature on petroleum removal.

\subsection{E. coli Removal}

\subsubsection{Effect of Reaction Time on E. coli Removal}

E. coli is widely present in the faeces of human and warm-blooded animals, and is an important index for evaluation of microorganisms in water. Hydrodynamic cavitation disinfection mechanism is not yet completely clear. The mechanical action theory is the most accepted one. That is, at the instant of a cavitation bubble collapses, the bubble produces a high-strength pressure pulse, accompanied by strong shock waves and micro jets. This shock pressure impairs the bacterial cell membrane and damages cell structure and functional components, leading to bacterial death. In addition, the oxidation effect of $\bullet \mathrm{OH}$ radicals generated by hydrodynamic cavitation process may also lead to bacterial death. Table 1 shows the E. coli removal rates achieved with different reaction times. E. coli removal rate increased with the increase of reaction time. Furthermore, E. coli removal rate reached $98.16 \%$ in $60 \mathrm{~min}$.

Table 1. Effect of reaction time on $E$. coli removal.

\begin{tabular}{|c|c|c|}
\hline Time (min) & E. coli density (MPN/100 ml) & E. coli removal rate (\%) \\
\hline 30 & $9.3 \times 10^{4}$ & 41.57 \\
\hline 60 & $2.9 \times 10^{3}$ & 98.16 \\
\hline 90 & $7.5 \times 10^{2}$ & 99.53 \\
\hline 120 & 3 & $>99.99$ \\
\hline
\end{tabular}

*Initial E. coli density: $1.6 \times 10^{5} \mathrm{MPN} / 100 \mathrm{ml}$, water temperature $25^{\circ} \mathrm{C}$.

\subsubsection{Effect of Water Conductivity on E. coli Removal}

To further investigate $E$. coli removal by hydrodynamic cavitation, two water samples (i.e., sample I and sample II) with conductivity of $723.0 \mu \mathrm{s} / \mathrm{cm}$ and $1268.0 \mathrm{us} / \mathrm{cm}$, respectively, were prepared by adding NaCl. Both samples have an initial E. coli density of $1.6 \times 10^{5} \mathrm{MPN} / 100 \mathrm{ml}$. Table 2 shows the effect of water conductivity on $E$. coli removal at $25^{\circ} \mathrm{C}$. A large number of $E$. coli were removed at high conductivity, which demonstrated that water conductivity had a 
great influence on bacterial removal. Salts reduce water tensile strength, which is favorable for cavitation generation. In the meantime, water with high conductivity contains more gas cores, which is also conducive to form cavitation. Therefore, the increase of water's conductivity enhanced bacterial removal rate.

Table 2. Effect of water conductivity on $E$. coli removal.

\begin{tabular}{|c|c|c|}
\hline \multirow{2}{*}{$\begin{array}{c}\text { Time } \\
(\text { min) }\end{array}$} & Sample1 & E. coli removal rate (\%) \\
\cline { 2 - 3 } & 45.76 & 98.21 \\
\hline 30 & 98.89 & 99.13 \\
\hline 60 & 99.02 & $>99.99$ \\
\hline 90 & $>99.99$ & $>99.99$ \\
\hline
\end{tabular}

\section{CONCLUSION}

The hydrodynamic cavitation can effectively remove organic pollutants and microorganisms based on its oxidation process to generate strong oxidizing of the $\bullet \mathrm{OH}$ radicals. The results showed that hydrodynamic cavitation was effective in colority, COD, petroleum and E. coli removal from water. The removal rate can be improved with the increase of reaction time and temperature. Under experimental conditions, the removal rate of colority, COD and petroleum pollutant was $80.0 \%, 72.13 \%$ and $70.00 \%$, respectively. In addition, the E. coli removal rate was more than $99.99 \%$. As a new type of water treatment technology, hydrodynamic cavitation has characteristics of simple setup, convenient operation and low maintenance cost and has the advantages of high efficiency, energy saving and environmental friendly. Hydrodynamic cavitation can be used not only as a stand-alone water treatment process, but also could be used in conjunction with other water treatment processes, as well as to further improve the treatment effect. Water treated by hydrodynamic cavitation can meet the national standards for effluent discharge and be reused effectively. In summary, there is a vast application prospect for hydrodynamic cavitation in water treatment.

\section{CONFLICT OF INTEREST}

The authors confirm that this article content has no conflict of interest.

\section{ACKNOWLEDGEMENTS}

This work was supported by the National Natural Science Foundation of China (No.51478461) and Key Projects of Tianjin Science and Technology Support Plan (No.10ZCGYSH02000)

\section{REFERENCES}

[1] Arrojo S, Benito Y. A theoretical study of hydrodynamic cavitation. Ultrason Sonochem 2008; 15(3): $203-11$. [http://dx.doi.org/10.1016/j.ultsonch.2007.03.007] [PMID: 17532249]

[2] Arrojo S, Benito Y, Tarifa AM. A parametrical study of disinfection with hydrodynamic cavitation. Ultrason Sonochem 2008; 15(5): 903-8. [http://dx.doi.org/10.1016/j.ultsonch.2007.11.001] [PMID: 18077202]

[3] Gogate PR. Cavitational reactors for process intensification of chemical processing applications: a critical review. Chem Eng Process Process Intens 2008; 47(4): 515-27. [http://dx.doi.org/10.1016/j.cep.2007.09.014]

[4] Gogate PR, Pandit AB. A review of imperative technologies for wastewater treatment I: oxidation technologies at ambient conditions. Adv Environ Res 2004; 8(3): 501-51. [http://dx.doi.org/10.1016/S1093-0191(03)00032-7]

[5] Balasundaram B, Pandit AB. Selective release of invertase by hydrodynamic cavitation. Biochem Eng J 2001; 8(3): 251-6. [http://dx.doi.org/10.1016/S1369-703X(01)00114-0]

[6] Bis M, Montusiewicz A, Ozonek J, Pasieczna-Patkowska S. Application of hydrodynamic cavitation to improve the biodegradability of mature landfill leachate. Ultrason Sonochem 2015; 26: 378-87. [http://dx.doi.org/10.1016/j.ultsonch.2015.03.003] [PMID: 25771333]

[7] Braeutigam P, Franke M, Schneider RJ, Lehmann A, Stolle A, Ondruschka B. Degradation of carbamazepine in environmentally relevant concentrations in water by Hydrodynamic-Acoustic-Cavitation (HAC). Water Res 2012; 46(7): 2469-77. [http://dx.doi.org/10.1016/j.watres.2012.02.013] [PMID: 22365175]

[8] Capocelli M, Musmarra D, Prisciandaro M, et al. Chemical effect of hydrodynamic cavitation: Simulation and experimental comparison. AIChE J 2014; 60(7): 2566-72.

[http://dx.doi.org/10.1002/aic.14472] 
[9] Capocelli M, Prisciandaro M, Lancia A, et al. Hydrodynamic cavitation of p-nitrophenol: A theoretical and experimental insight. Chem Eng J 2014; 254: 1-8.

[http://dx.doi.org/10.1016/j.cej.2014.05.102]

[10] Ghayal D, Pandit AB, Rathod VK. Optimization of biodiesel production in a hydrodynamic cavitation reactor using used frying oil. Ultrason Sonochem 2013; 20(1): 322-8. [http://dx.doi.org/10.1016/j.ultsonch.2012.07.009] [PMID: 22922070]

[11] Gore MM, Saharan VK, Pinjari DV, Chavan PV, Pandit AB. Degradation of reactive orange 4 dye using hydrodynamic cavitation based hybrid techniques. Ultrason Sonochem 2014; 21(3): 1075-82. [http://dx.doi.org/10.1016/j.ultsonch.2013.11.015] [PMID: 24360991]

[12] Jyoti KK, Pandit AB. Water disinfection by acoustic and hydrodynamic cavitation. Biochem Eng J 2001; 7(3): $201-12$. [http://dx.doi.org/10.1016/S1369-703X(00)00128-5]

[13] Jyoti KK, Pandit AB. Effect of cavitation on chemical disinfection efficiency. Water Res 2004; 38(9): $2248-57$. [http://dx.doi.org/10.1016/j.watres.2004.02.012] [PMID: 15142785]

[14] Mezule L, Tsyfansky S, Yakushevich V, et al. A simple technique for water disinfection with hydrodynamic cavitation: Effect on survival of Escherichia coli. Desalination 2009; 248(1): 152-9.

[http://dx.doi.org/10.1016/j.desal.2008.05.051]

[15] Sawant SS, Pandit AB, Anil AC, et al. Effect of hydrodynamic cavitation on zooplankton: A tool for disinfection. Biochem Eng J 2008; 42(3): 320-8. [http://dx.doi.org/10.1016/j.bej.2008.08.001]

[16] Suslick KS, Mdleleni MM, Ries JT. Chemistry induced by hydrodynamic cavitation. J Am Chem Soc 1997; 119(39): 9303-4. [http://dx.doi.org/10.1021/ja972171i]

[17] Wang X, Zhang Y. Degradation of alachlor in aqueous solution by using hydrodynamic cavitation. J Hazard Mater 2009; 161 (1): 202-7. [http://dx.doi.org/10.1016/j.jhazmat.2008.03.073] [PMID: 18462876]

[18] Kumar P, Moholkar VS. Numerical assessment of hydrodynamic cavitation reactors using organic solvents. Ind Eng Chem Res 2011; 50(8): 4769-75.

[http://dx.doi.org/10.1021/ie1025024]

(C) Liu et al.; Licensee Bentham Open.

This is an open access article licensed under the terms of the Creative Commons Attribution-Non-Commercial 4.0 International Public License (CC BY-NC 4.0) (https://creativecommons.org/licenses/by-nc/4.0/legalcode), which permits unrestricted, non-commercial use, distribution and reproduction in any medium, provided the work is properly cited. 